\title{
LA PRESENCIA DEL GIGANTE EN EL CICLO AMADISIANO: UN PARADIGMA ANTROPONÍMICO CABALLERESCO
}

\author{
MARÍA Coduras BrunA ${ }^{1}$ \\ Universidad de Zaragoza
}

\section{RESUMEN}

El gigante o jayán es un tipo constante en los libros de caballerías. Simbolizando la desmesura, la soberbia y la brutalidad, representa el mal y se opone al caballero, arquetípicamente virtuoso. En esta ocasión, nos proponemos analizar su presencia en el ciclo amadisiano para, desde él, extraer una poética antroponímica propia de la raza gigantea extensible a todo el género caballeresco.

PALABRAS ClaVE: Gigante, antroponimia, libros de caballerías, ciclo amadisiano.

\section{Abstract}

The giant or jayán is a constant type in romance of chivalry. Symbolizing savageness, arrogance and brutality, represents evil, opposite the knight, vitue's archetype. On this occasion, we analyze the gi-

1 Este trabajo se inscribe en el grupo investigador «Clarisel» (H34) de la Universidad de Zaragoza, con la participación económica del Departamento de Ciencia, Tecnología y Universidad del Gobierno de Aragón y del Fondo Social Europeo, y en el Proyecto I+D «Reescrituras y relecturas: hacia un catálogo de obras medievales impresas en castellano hasta 1600» (FFI2012-32259), subvencionado por el Ministerio de Economía y Competitividad.

Recibido: 25-07-2014 / Aceptado: 20-10-2014 
ant's presence in the Amadisian cycle, deducing an anthroponimic poetics of giants extensible to all of the chivalric genre.

KEY wORDS: Giant, anthroponymy, chivalric romances, Amadisian cycle.

\section{GigANTES Y GigANTAS EN EL CICLO AMADISIANO}

Los gigantes, como los enanos, constituyen un grupo de personajes imprescindible en los libros de caballerías. ${ }^{2}$ Ambos se hallan en los extremos del modo natural del hombre por su talla y sus defectos e imperfecciones (Lucía Megías, 2003), la desmesura física y moral en el caso de los primeros. ${ }^{3}$

Un gigante prototípico es enorme, velludo, de pelo crespo, feo, bravo, furioso y soberbio, como sucede con Brigión que «parescía una torre entre almenas. Era vermejo y crespo [...] e dezían que era el más sobervio de todos» $(F, 17:$ fol. d3r), mientras que un caballero está bien formado, es alto, extremadamente hermoso, valiente, leal, justo y esforzado, y una doncella o dama es hermosa, normalmente rubia, de largos cabellos, piel clara, mejillas rosadas, discreta, sabia, graciosa y virtuosa. ${ }^{4}$

Las descripciones de los gigantes son escasas en los primeros textos caballerescos castellanos, sucintamente «un nombre (gigante o jayán), un adjetivo (desmesurado, desaforado, descomunal) o una comparación (como una torre)» (Lucía Megías, 2003), pues fundamentalmente se pretendía concretar sus defectos. Sin embargo, estas se amplían conforme avanza el siglo XVI, llegando a semejarse en ocasiones a las descripciones de monstruos e incluso a dificultar su adscripción a uno u otro

2 Dada la referencia constante a las entregas del ciclo amadisiano, se emplearán las siguientes abreviaturas para referirse a cada una de ellas: Amadís de Gaula (AG), Sergas de Esplandián (S), Florisando (F), Lisuarte de Grecia de Feliciano de Silva (LG), Lisuarte de Grecia de Juan Díaz (LD), Amadís de Grecia (AGr), Primera y Segunda Parte de Florisel de Niquea (FNI-II), Tercera Parte de Florisel de Niquea (FNIII), Silves de la Selva (SS) y Cuarta Parte de Florisel de Niquea (FNIV).

3 Es curioso que el gigante no aparezca prácticamente en el corpus caballeresco breve, hecho que X. Luna Mariscal explica por la primacía de la aventura en sus trabajos «El gigante ausente: transformación y pervivencia de un tema literario en las historias caballerescas breves», en Aurelio González, Lilia von der Walde y Concepción Company (eds.), Temas, motivos y contextos medievales, México, El Colegio de México-Universidad Nacional Autónoma de México-Universidad Autónoma Metropolitana, 2008, pp. 45-59; e Índice de motivos de las Historias caballerescas breves, Vigo, Editorial Academia del Hispanismo, 2013. Así, de los quince relatos editados por Baranda (1995), solo se encuentra la figura del gigante de manera significativa en la Historia del Emperador y los doce pares de Francia, con Fierabrás y Ferragut.

4 La atroz imagen simbólica de los gigantes tiene sus raíces en la mitología, la tradición bíblica y el folclore, como afirma F. Acero Yus, «Los gigantes en el Quijote de Cervantes: revisión de un motivo de la literatura caballeresca», Espéculo: Revista de Estudios Literarios, 32 (2006), sin paginación. Para más información acerca de la relación de los gigantes con la tradición literaria y francesa anterior al Quijote, resulta imprescindible el trabajo de F. Márquez Villanueva, «El tema de los gigantes», en Fuentes literarias cervantinas, Madrid, Gredos, 1973, pp. 297-311. Para conocer más datos acerca del gigante soberbio, consultar Cuesta Torre, «Nuevas formulaciones del tópico del caballero soberbio en el Olivante de Laura de Antonio de Torquemada», en La maravilla escrita. Antonio de Torquemada y el Siglo de Oro, León, Universidad de León, 2005, pp. 321-342. 
grupo como sucede con Furior Cornelio, hijo del gigante Bravanadel y su esposa, «dessemejada jayana». Bravanadel, enamorado de una de las vacas de sus pastos, engendra en su esposa un verdadero monstruo, «de la cinta arriba era de forma de hombre y de la cinta para baxo de toro» $(A G r, 124$ : 547); sin embargo, sus progenitores son gigantes. Y, en los extremos, incluso llega a haber gigantes afectados, como ha analizado Campos Rojas: «las características del amansamiento, cortesía y mesura son llevadas a un extremo tal, que los gigantes pierden gran parte de su sentido original; quedan minimizados, contradictorios y ridiculizados» (Campos, 2009: 493).

En el caso del ciclo amadisiano, encontramos jayanes arquetípicos. Bravos como Albadán, «jayán bravo» (AG, I, 3: 267), Madarque, «gigante bravo» (AG, III, com.: 961), Alboçén, «de muy espantable ferocidad y fortaleza» (LD, 171: fol. 202r), Alastradolfo, «un tan esquivo jayán que en todas las orientales ínsolas no se falla su igual en grandeza y braveza» (FNI-II, 42: fol. 209r), Breo, «bravo y esquivo en todas malas maneras enemigos de la virtud» (FNI-II, II, 29: fol. 185v), o Madasavil, «bravo y esquivo jayán en demasía» (FNI-II, 56: fol. 237r); desemejados como Furión, «bestia mala dessemejada sin talle y sin razón» $(S, 6: 148)$, Bragadán, «de feo gesto y medrosa catadura, y avía los cabellos bermejos y la barva a maravilla» (LD, 176: fol. 208v), o Enceleo, «el más fuerte y el más desemejado del mundo así en la grandeza de su cuerpo como en fortaleza nunca falló gigante que él no fuesse mayor un pie» $(L D, 20$ : fol. 30v); y temidos como Ficarón, «a maravilla valiente, que aun entre los jayanes era tenido y temido por su persona y grande esfuerço» $(F, 112$ : fol. 123r), destacándose siempre su talla, como sucede con Bracino y Bracafeo que «eran más altos que la cerca de la cibdad» (SS, 38: fol. 40v) o de nuevo Furión, «un gigante mancebo de días [...] tan grande de cuerpo que cosa estraña era de lo ver» $(S, 6: 148)$.

Como ya se ha señalado, el mayor defecto de los gigantes es la soberbia y la idolatría, pues habitualmente son paganos $\mathrm{y}$, por tanto, uno de los principales enemigos del caballero, símbolo del cristianismo. ${ }^{5}$ El gigante es un ser soberbio ajeno a toda norma social, lo cual se evidencia en sus palabras; así, la desmesura física y moral va acompañada de la expresiva (Martín Romero, 2006). Aunque también existen gigantes buenos, como el padre de Malfadea que «aunque era jayán era de buenas condiciones y preciávase de ser justiciero y piadoso, y hazía muy buenas obras a todos los jayanes sus comarcanos» $(A G r, 40: 138)$. Otros obran una metamorfosis al convertirse al cristianismo, como ocurre con Balán, Cuadragante y Madarque en el $A G$,

\footnotetext{
J. J. Martín Romero, «El combate contra el gigante en los textos caballerescos», en Rafael Alemany, Josep Lluís Martos y Josep Miquel Manzanaro (eds.), Actes del X Congrés Internacional de l'Associació Hispànica de Literatura Medieval (Alacant, 16-20 setembre de 2003), Alacant, Institut Interuniversitari di Filologia Valenciana, 3, 2005, pp. 1105-1120, ha analizado la figura del gigante desde la perspectiva del combate, haciendo hincapié en los tópicos que caracterizan sus luchas con el caballero a partir de un corpus de trece textos caballerescos anteriores a 1519.
} 
Matroco y Frandalo en las Sergas, o Brucarinda en el Florisando. ${ }^{6}$ Finalmente a otros, aunque virtuosos, les puede la saña, como sucede con Gandalac que «no era fazedor de mal como los otros gigantes; antes era de buen talante, fasta que era sañudo, mas después que lo era hazía grandes cruezas» (AG, I, 3: 267).

Pero, ¿qué sucede con las gigantas? En este punto conviene señalar que el tratamiento y descripción de gigantas y jayanas dista mucho del de los gigantes, dado que muchas de ellas suelen ser hermosas, como sucede con Bandaguida o Brisaida. Recordemos algunas de sus descripciones en el ciclo amadisiano: Madasima «la muy fermosa» $(A G, \mathrm{II}, 54: 764)$, Arcalona es «brava giganta [...] aunque fermosa» $(L D, 141$ : fol. 167v), Gadalesa es «jayana moça y hermosa» de «ruvios cabellos» (FNIII, 43: 129), Briangia es «jayana y tan estremada en hermosura que dizen que en toda la Grande Asia no ay donzella tan hermosa como esta reina de que os digo» (FNIII, 90: 284) o Galacinda es «donzella jayana, y assaz era hermosa aunque estava flaca, vestida de una ropa de terciopelo pardo, y un tocado en su cabeça de zarzahanes de la mesma color» (FNIV, II, 23: fol. 49r). Aunque, por supuesto, nos encontramos con jayanas equiparables a los gigantes como Andandona, «una giganta [...] la más brava y esquiva que en el mundo avía» (AG, III, 65: 980) o Gromadaça, «la giganta brava» (AG, II, 57: 817), fundamentalmente en los primeros textos, así como otras que destacan por su fealdad, como sucede con la «dessemejada» Gadabalassa (FNIV, II, 22: fol. 49r) o con Gadalfea, de rasgos ciclópeos,

todos se espantaron cuando la vieron de ver su fealdad. Sabed que era tamaña como jayana, y no tenía sino un ojo, y este en la mitad de la frente. Venía toda vestida de conchas de pescados muy menudas cosidas en una ropa que por el suelo de encima de un palafrén más de dos braças rastrava. En su cabeça traía un tocado muy alto hecho de conchas de caracoles por muy estraña manera en él texidos (AGr, 24: 86). ${ }^{7}$

Sin embargo, prima su carácter dulcificado debido también, quizá, a los matrimonios compensatorios entre gigantes y humanas. Por ejemplo, la hija de Darioleta se casa con Bravor en el Libro IV del Amadís de Gaula, filiación que explicaría cómo la presencia de la mujer dignifica y mejora la braveza y furia del linaje de los gigantes.

\footnotetext{
6 A veces la conversión religiosa va acompañada de un cambio de nombre. Así, Brucarinda, hija del gigante Bruterbo, cambiará su nombre por el de Breçaida al abrazar la fe cristiana. Pueden consultarse más casos en M. Coduras, La antroponimia en los libros de caballerías españoles: el ciclo amadisiano, Zaragoza, Universidad de Zaragoza, 2013.

7 Es singular el caso de la jayana Batalassa que recuerda en su descripción a la maga Melía: «una jayana muy vieja, tanto que de raíces parescía hecha [...] era grande y rezia» (FNIII, 28: 86). Recordemos que el rostro y las manos de Melía «parecían tan arrugados como las raízes de los árboles cuando más envejecidas y retuertas se muestran» $(S, 101: 557)$.
} 


\section{El GIGANTE EN CIFRAS EN EL CICLO AMADISIANO}

El gigante ocupa un lugar fundamental en el ciclo amadisiano. Un total de 185 de ellos desfilan por sus páginas (166 gigantes y 19 gigantas), lo que supone prácticamente un $16 \%$ de la nómina total, cifra nada desdeñable si tenemos en cuenta, además, que la presencia femenina se reduce al $27 \%$ y solo ronda el $10 \%$ en las plumas ajenas a Feliciano de Silva, como veremos más adelante. ${ }^{8}$
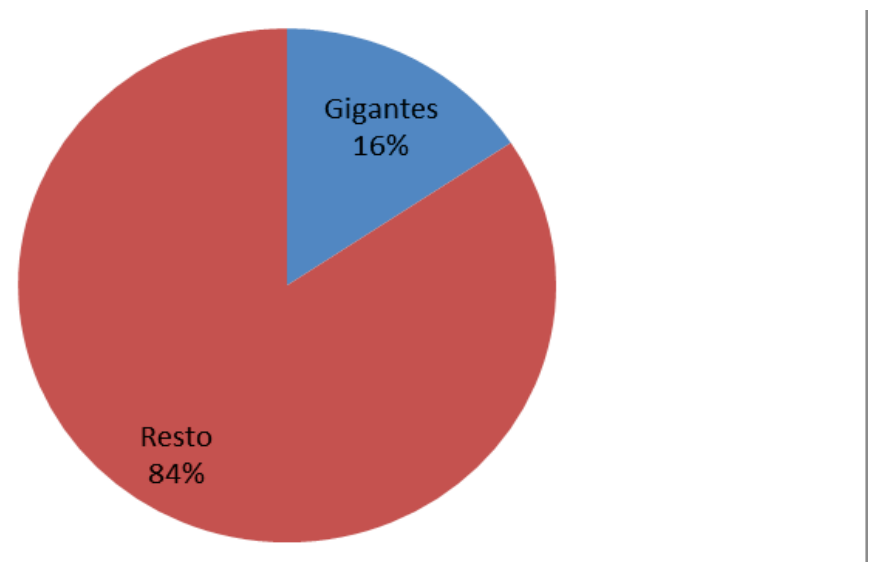

Gráfico 1. Porcentaje total de gigantes en el ciclo amadisiano

Si nos detenemos en cada uno de los libros que componen el ciclo amadisiano, obtendremos los siguientes datos:

- Amadís de Gaula (1508): cuenta con veinticuatro gigantes, de los cuales veinte son varones (Albadán, Albadançor, Andaguel, Balán, ${ }^{9}$ Bandaguido, Basagante, Bramandil, Bravor, ${ }^{10}$ Bravor, ${ }^{11}$ Cartadaque, Dandasido, Famongomadán, Gadancuriel, Galeote, ${ }^{12}$ Gasquilán, Gavus, Lindoraque, Madanfabul y Madarque) y cuatro son hembras (Andandona, Bandaguida, Gromadaça y Madasima ${ }^{13}$ ). Estos suponen un 9,26\% del total de los personajes, si bien aquí habría que considerar otros parámetros como su adscripción al Amadís

\footnotetext{
8 Para la extracción de todos los datos numéricos y estadísticos de este trabajo he empleado el Diccionario de nombres del ciclo amadisiano (DINAM) < dinam.unizar.es> (Coduras, 2013). Remito al mismo para obtener más información acerca de los personajes. Se ha tomado como referencia la cifra de 1183 personajes con antropónimo en el ciclo amadisiano; en ella no se han tenido en cuenta los personajes alegóricos (Congoja, Conocimiento, Desesperación, Dolor, Esperanza, Fe, Fortaleza, Honra, Justicia, Misericordia, Pena, Pensamiento, Razón, Sufrimiento, Temperanza y Tormento) ni aquellos monstruos que, por sus características físicas, no facilitan una clasificación genérica racional (Bestia Serpentaria, Endriago, Leonça o Tigreleo).

9 Balán, padre de Bravor y abuelo de Galeote.

10 Bravor, hijo de Balán y padre de Galote.

11 Bravor, padre de Galeote el Brun.

12 Galeote el Brun.

13 Hija del gigante Famongomadán y esposa de Galvanes.
} 
primitivo o al medinés Montalvo (Avalle-Arce, 1990). ${ }^{14}$

- Sergas de Esplandián (1510): suman un total de quince gigantes, una jayana (Madasima) y catorce varones, de los que tan solo seis son de nueva creación (Bramato, Forón, Furión, Grafión, Leonato y Matroco). Constituyen un 9,37\% de la nómina total. ${ }^{15}$

- Florisando (1510): aparecen un total de veintiocho gigantes, tres jayanas y veinticuatro gigantes, de los cuales veintiuno son de nueva creación (Adriano, Arlote, Brigión, Brucarinda, Bruterbo, Bulbaçén, Bultrafo, Crebón, Ficarón, Gualtero, Longibel, Malabraçán, Malobato, Nazarón, Opicio, Orián, Palidón, Pavorante, Rolando, Saliandro, Satirón y Turón). Suponen un 18,54\% de la nómina total. ${ }^{16}$

- Lisuarte de Grecia (1514): cuenta con nueve gigantes, ocho varones y una

14 Conviene señalar que no siempre hemos considerado gigantes a todos aquellos personajes de talla gigantea o semigigantes. Una de las razones para tomar dicha decisión es que, muchas veces, especialmente en las primeras entregas del ciclo amadisiano, dicha circunstancia favorece que se comporten de forma menos fiera y posean un carácter más bondadoso o virtuoso. Además, en estos casos suelen ser descritos como «cavalleros de gran cuerpo» y no como «gigantes» o «jayanes» en el texto. Podríamos mencionar los siguientes ejemplos: Abiés $(A G)$ y Cuadragante $(A G)$ son caballeros de tamaño giganteo, Frandalo es «caballero grande de cuerpo y muy feo de rostro» $(S, 33: 272)$, «el caballero era muy membrudo, como aquel que venía de parte de su madre de los más fuertes jayanes de todo el señorío de Persia, e de su padre de muy valientes y esforçados [cavalleros], que así era él» (S, 34: 276); y Ardán Canileo es «caballero señalado en el mundo y de gran prez y fecho de armas (...) era de sangre de gigantes [...] no era descomunalmente grande de cuerpo, pero era más alto que otro hombre que gigante no fuesse» (AG, II, 61: 866). En la mayoría de las ocasiones se ajustan a la descripción de gigantes y jayanes, pero se menciona explícitamente que no lo son, como ocurre en estos casos del FNIII: los hermanos Galtazar, Aurizán y Galterio «no eran jayanes» mas lo parecían ya que «eran muy grandes y membrudos. Avían los ojos estallados y grandes, muy anchos de ventanas de narizes, y los labrios muy gruessos eran muy bermejos de color. Los cabellos y barvas avían de color de cerdas de buey» (FNIII, cap. 49, p. 145); Bruzerbo el Crespo es «un caballero que poco para jayán le faltava, aunque en ser membrudo parescía sobrar en fuerças y valentía a otro que jayán fuesse» (FNIII, 101: 316); Bultazar es «un cavallero tan grande de cuerpo que poco para jayán le faltava» (FNIII, 23: 66); y Bruzerbo, rey de Gaza, es «caballero de gran cuerpo [...] el gesto negro y de brava catadura, los cabellos avía crespos, y era tan membrudo que poco para gigante le fallecía» (FNIII, 6: 20). Por su parte, Galeote y Bravor, hijo de Bravor y de Galeote, respectivamente, solo son gigantes por vía paterna. Sin embargo, sí hemos considerado a ambos, del linaje de los Brunes, como gigantes, puesto que así reza en el propio texto: «y porque sucedieron de aquel jayán, fijo de Balán, siempre los llamaron gigantes, aunque en sus cuerpos no se conformassen con la grandeza dellos por la parte de la mujer [...]; y también porque todos los de aquel linaje fueron fuertes y valientes en armas, y con mucha parte de la sobervia y follonía donde descendían» ( $A G, I V, 129: 1678)$. Para más información acerca del linaje de los Brunes, consultar Cuesta Torre «"Si avéis leído o leyerdes el libro de don Tristán y de Lançarote, donde se faze mención destos Brunes": Bravor, Galeote y el Caballero Anciano del Tristán castellano en el Amadís de Montalvo», en «Amadís de Gaula»: quinientos años después. Estudios en homenaje a Juan Manuel Cacho Blecua, Alcalá de Henares, Centro de Estudios Cervantinos, 2008, pp. 147-173.

15 Albadán, Balán, Basagante, Bramato, Bravor, Cartadaque, Famongomadán, Forón, Furión, Gasquilán, Grafión, Leonato, Lindoraque, Madsima y Matroco.

16 Adriano, Arlote, Balán, Bravor, Brigión, Brucarinda, Bruterbo, Bulbaçén, Bultrafo, Crebón, Famongomadán, Ficarón, Gromadaça, Gualtero, Longibel, Madasima, Malabraçán, Malobato, Matroco, Naçarón, Opicio, Orián, Palidón, Pavorante, Rolando, Saliandro, Satirón y Turón. 
hembra, de los cuales seis son de nueva creación (Almatrafa, Brutillón, Filorte, Golfón, Grifilante y Gudulfre). Suponen un 5,76\% de la nómina total. ${ }^{17}$

- Lisuarte de Grecia (1526): se registran cincuenta y cinco gigantes, cincuenta $\mathrm{y}$ tres varones y dos hembras, de los cuales treinta y tres son de nueva creación (Albocén, Albumazar, Almadarol, Almandrago, Arcalona, Balán, Balaín, Bragadán, Brucalán, Brutervo, Bucar, Caurón, Cutroferón, Dramirón, Drusomago, Enceleo, Filesarfo, Focias, Geolardo, Gromolías, Grovalaz, Mabulcán, Macareo, Madarque, Madrusián, Mondragor, Nabuzardo, Nitroferón, Ridalfo, Tanáis, Tersivandro, Vadaganir y Zoandro). Constituyen un $18,51 \%$ de la nómina total. ${ }^{18}$

- Amadís de Grecia (1530): reúne a veintiún gigantes, dieciocho varones y tres féminas, de los que dieciéis son de nueva creación (Argantadel, Bravadanel, Fradalón Cíclopes, Fraudalón, Fustión, Gadalfe, Gadalfea, Leofán, Leorico, Madarán, Mascarón, Montón, Mostruofurón y Siguelos). Suponen un 10\% de la nómina total. ${ }^{19}$

- Primera y Segunda Parte de Florisel de Niquea de Florisel de Niquea (1532): se experimenta un descenso en el número de gigantes, pues solo aparecen catorce, todos ellos varones, de los cuales la práctica totalidad, doce, son de nueva creación (Alastradolfo, Baldarín, Bostrolfo, Bradanel, Braforán, Breo, Brugiante Cinofal, Madafarán, Madasavil Cornelio, Mordobuseo, Sizirfán y Zambanel). Conforman un $7,48 \%$ de la nómina total. ${ }^{20}$

- Tercera Parte de Florisel de Niquea (1535): reúne a veintinueve gigantes, veintitrés varones y seis féminas, de los cuales veinticinco son de nueva creación (Aurizán, Baralasta, Batalasa, Bazarán, Bazaranco, Bazarón, Bosdrolfo, Briangia, Bruzerbo, Bruzerbo, Bruzo Cornelio, Burdeo, Gadalesa, Gadalón, Gadalote, Galpatrafo, Galtazar, Galterio, Gandalate, Garçaraça, Gregasta,

\footnotetext{
17 Almatrafa, Balán, Bravor, Brutillón, Filorte, Gasquilán, Golfón, Grifilante y Gudulfre.

18 Andriano, Albadán, Albocén, Albumazar, Almadarol, Almandrago, Arcalona, Arlote, Balán, Balán, Balaín, Basagante, Bragadán, Bravor, Brucalán, Bruterbo, Brutervo, Bucar, Bultrafo, Caurón, Cutroferón, Dramirón, Drusomago, Enceleo, Famongomadán, Filesarfo, Focias, Furión, Galeote, Gandalz, Gasquilán, Geolardo, Gromolías, Grovalaz, Mabulcán, Macareo, Madarque, Madarque, Madasima, Madrusián, Malobato, Matroco, Mondragor, Nabuzardo, Nitroferón, Orián, Pavorante, Ridalfo, Rolando, Saliandro, Tanáis, Tersivandro, Turón, Vadaganir y Zoandro. Balán el Salvaje, hijo de Tanáis. Madarque, hijo de Gasquilán y nieto de Madarque.

19 Argantadel, Balán, Balán, Bravadanel, Bravor, Fradalón Cíclopes, Fradamela, Fraudalón, Fustión, Gadalfe, Gadalfea, Galeote, Leofán, Leorico, Madarán, Malfadea, Mascarón, Matroco, Montón, Mostruofurón y Siguelos.

20 Alastradolfo, Balán, Baldarín, Bostrolfo, Bradanel, Braforán, Breo, Brugiante Cinofal, Madafarán, Madasavil Cornelio, Mordobuseo, Mostruofurón, Sizirfán y Zambanel.
} 
Mandroco Masfandel). ${ }^{21}$ Suponen un 10,78\% del total. ${ }^{22}$

- Silves de la Selva (1546): Pedro de Luján concede una menor importancia a los gigantes; hay un total de quince, todos varones, de los cuales doce son de nueva creación (Astrobando, Bracafeo, Bracino, Brusín, Dramadón, Leopando, Macredo, Mangadón, Marcafeo, Marfondo, Mandrago y Monleo). Constituyen un $8,42 \%$ de la nómina total. ${ }^{23}$

- Cuarta Parte de Florisel de Niquea (1551): cuenta con cuarenta gigantes, treinta y siete varones y tres hembras, de los cuales treinta y cinco son de nueva creación (Alastrasorón, Badaburel, Badarán Badabul, Basdagarel, Bastandulfo, Bastrafo, Brabosor, Brandabadal, Brosón, Bruldelfo, Bultasarfo, Espantolfo, Furibundo, Gadabalassa, Galacinda, Gandafadel, Gastandulfo, Gazizazel, Grisilón, Grobodón, Lazarán, Lisnadoque, Madarón, Madasinel Cornelio, Mordaserón Cornelio, Mordofeo, Mostruón, Nastarofo, Rugión, Roquedos, Safabul, Sardapión, Serpentón y Gandagadul). Suponen el 21,85\% del total. ${ }^{24}$

Así, el porcentaje se mantiene estable en torno al $10 \%$ en el $A G$, las $S$, el $S S$ y las entregas de Feliciano de Silva, con la excepción del FNIV en el que se observa un claro repunte que alcanza prácticamente el $22 \%$. De otro lado, las continuaciones heterodoxas, el $F$ y el $L D$, parecen otorgar una mayor relevancia a la raza gigantea, que roza el $20 \%$ en cada uno de estos textos.

Por otra parte, la presencia de los gigantes en el ciclo amadisiano es elevada si la comparamos con otros grupos tipológicos (escuderos, enanos, magos, monstruos) o con las mujeres, dado que el porcentaje de gigantes y mujeres es prácticamente idéntico en algunos libros del ciclo, concretamente en las continuaciones heterodoxas, el Florisando (18\%) y el Lisuarte de Grecia de Juan Díaz (18\%). Estos datos resultan más llamativos si no los tomamos aisladamente sino dentro del contexto de todo el ciclo amadisiano, de tal forma que observamos cómo Páez de Ribera y Juan Díaz conceden una importancia mucho mayor a los gigantes que a los personajes femeninos, ya que

21 Aurizán, Balán, Baralasta, Basagante, Batalasa, Bazarán, Bazaranco, Bazarón, Bosrolfo, Breo, Briangia, Bruzerbo, Bruzerbo, Bruzo Cornelio, Burdeo, Famongomadán, Gadalesa, Gadalón, Gadalote, Galpatrafo, Galtazar, Galterio, Gandalate, Garçaraça, Gregasta, Madarán, Mandroco, y Masfandel.

22 Bruzerbo el Crespo, rey de los masagetas. Bruzerbo, rey de Gaza.

${ }^{23}$ Astrobando, Balán, Bracafeo, Bracino, Breo, Brusín, Dramadón, Leopando, Macredo, Mangadón, Marcafeo, Marfondo, Matroco, Mondrago y Monleo.

24 Alastrasorón, Badaburel, Badarán Badabul, Balán, Basdagarel, Bastandulfo, Bastrafo, Brabosor, Brandabadal, Brosón, Bruldelfo, Bultasarfo, Espantolfo, Fradalón Cíclopes, Furibundo, Gadabalassa, Galacinda, Gandafadel, Gastandulfo, Gazizazel, Grisilón, Grobodón, Lazarán, Leofán, Lisnadoque, Madarón, Madasinel Cornelio, Mandoco, Montón, Mordaserón Cornelio, Mordofeo, Mostruón, Nastarofo, Rugión, Roquedos, Safabul, Sardapión, Serpentón y Gandagadul. 
solo un 3\% de mujeres de nueva creación en el F se deben a Páez de Ribera y un 9\% a Juan Díaz en el LD y, sin embargo, Páez introduce un 11,29\% de gigantes de su puño y letra y Juan Díaz un 17,74\%. Así, combinando todos los datos anteriores, obtenemos el siguiente gráfico, en el que se observa la primacía gigantea en el Lisuarte de Grecia de Juan Díaz y la Cuarta Parte del Florisel de Niquea de Feliciano de Silva, última entrega del ciclo amadisiano:
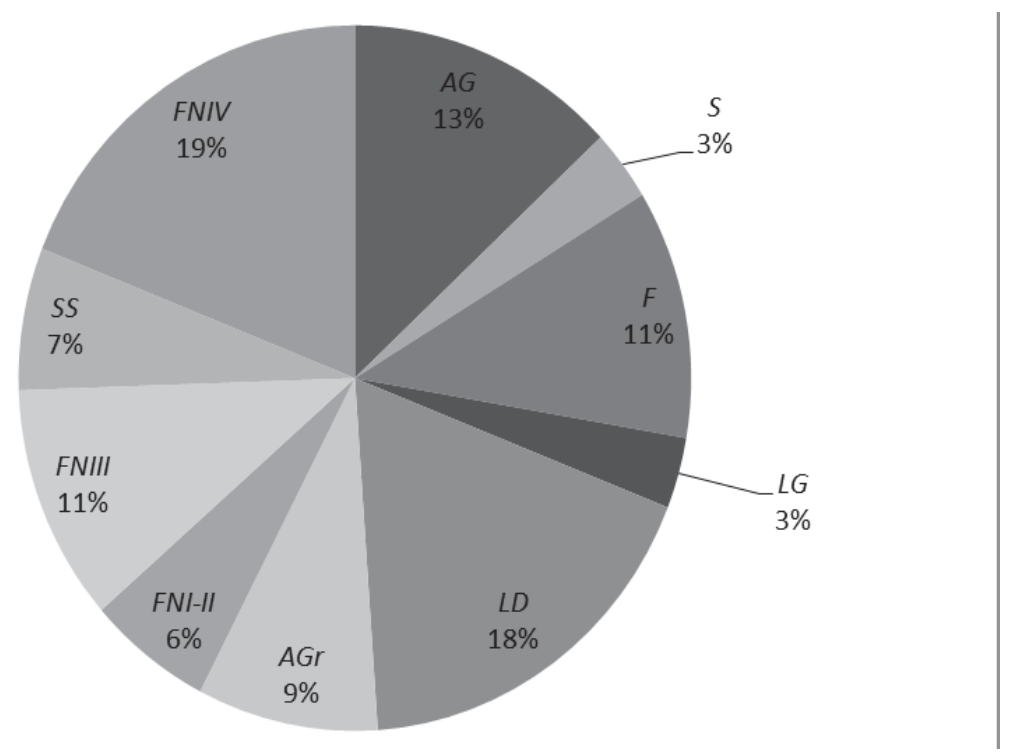

Gráfico 2. Gigantes de nueva creación introducidos en cada una de las entregas del ciclo amadisiano

\section{LA ANTROPONIMIA GIGANTEA EN EL CICLO AMADISIANO}

La naturaleza de los nombres de los gigantes en el Amadís de Gaula fue uno de los aspectos antroponímicos más estudiados por Avalle-Arce (1990). Sin embargo, nadie se ha ocupado con detenimiento del análisis de los mismos en las Sergas y el resto del ciclo amadisiano. Mientras que los gigantes del $A G$ poseen nombres propios difícilmente interpretables atendiendo a su forma, los de las $S$ son mucho más claros semánticamente.

En el AG los antropónimos de los gigantes todavía no son parlantes. En las $S$ empieza a notarse la mano de Montalvo con la introducción de la antroponimia de raíz grecolatina (aplicable a toda la tipología de personajes), circunstancia que se mantendrá hasta el final del ciclo con la particularidad de que en el FNI-II y el FNIII hay un cierto oscurecimiento de los nombres que parece deberse a una vuelta a la antroponimia gigantea del $A G$.

Los gigantes que aparecen en el Libro I del AG, como Gandalac, son de clara procedencia artúrica; sin embargo, a partir del Libro II, su aspecto resulta más exótico 
(Madanfabul, Famongomadán). ${ }^{25}$ En el libro III aparecen, fundamentalmente, los gigantes Bandaguido y Bandaguida, de raíz aparentemente germánica y, en el Libro IV, el linaje de los Brunes ha sido trasvasado directamente de la materia artúrica.

Por su parte, los nombres de los gigantes que aparecen en las Sergas son bastante más transparentes y fácilmente interpretables; así los antropónimos Furión (del latín furia), Bramato (del verbo bramar, del gótico bramôn 'dar bramidos', 'manifestar con voces articuladas o inarticuladas y con extraordinaria violencia la ira de que está poseída'), Leonato (del latín leo, leonis 'león' + natus 'nacido'), o Matroco (del latín mater, matris 'madre' por su relación tan estrecha con su progenitora). Son estos nombres de raíz latina que permiten atisbar unos rasgos compositivos relacionados con la desmesura moral y la violencia extrema, a través de formantes como furia o el sufijo aumentativo -ón, recurrentes en el resto de continuaciones del ciclo amadisiano para la raza gigantea, como veremos.

Los nombres de gigantes del Florisando siguen las pautas y mecanismos de formación nominal amadisianos, predominando la construcción mediante el sufijo aumentativo -ón (Brigión, Crebón, Ficarón, Naçarón, Palidón, Satirón, Turón). ${ }^{26}$ La gran presencia del gigante en el texto se explicaría por la concentración del mal en la figura del gigante, representante del infiel, y la eliminación de todos aquellos monstruos o elementos diabólicos tan frecuentes en el resto de libros de caballerías.

En el Lisuarte de Grecia de Feliciano de Silva los antropónimos de gigantes siguen por los mismos derroteros mientras que en el homónimo de Juan Díaz se produce una circunstancia singular. El Palmerín de Inglaterra tomará prestados los antropónimos de cinco de sus gigantes con ligeras modificaciones, manteniendo en el texto de acogida su condición: Nabuzardo (LD)-Albuzarco(PI), Almandrago

${ }_{25}$ Estos últimos probablemente inspiraron los antropónimos jocosos presentes en la celebérrima aventura quijotesca de los rebaños de ovejas $(D Q, \mathrm{I}, 18)$. El cambio de la antroponimia gigantea de un libro a otro del Amadís ha llevado a Avalle-Arce a desvincular su creación de Rodríguez de Montalvo, al que atribuye exclusivamente la de las Sergas: «No me inclino por la atribución a Montalvo de los estrepitosos y rimbombantes nombres de sus jayanes (Famongomadán, Cartadaque, Madanfabul), porque si bien hay una semejante epidemia de jayanes en las Sergas de Esplandián, estos tienen nombres más moderados, más de entrecasa, se podría decir, tales como Frandalo, Bramato, Matroco» (J. B. Avalle-Arce, Amadís de Gaula: el primitivo y el de Montalvo, México, Fondo de Cultura Económica, 1990, p. 246).

26 Satirón queda emparentado con la figura mitológica del sátiro, destacando su carácter lascivo y lujurioso; Palidón (del latín pallidus 'pálido'); Crebón (del latín creber 'espeso, abundante'), en relación con los cabellos de los gigantes; Turón (del latín turare 'durar'), Brigión (de briega o brega 'questión, reyerta, riña o pendencia la qual es comúnmente entre gente vulgar y ordinaria, con vocería, confusión y alboroto, por suceder mui frecuentemente en pareges públicos', Diccionario de Autoridades, 1726); Ficarón (del latín *figere 'calavar, hincar' o del término ficante que, en lengua de germanía, valía por jugador o tramposo (Chamorro, 2002: 402); Pavorante (del latín pavor, pavoris 'pavor'); Arlote (arlote, 'holgazán, bribón', DRAE); Bruterbo (del latín brutus 'bruto, irracional, necio'); y Longibel remite a los Triunfos de Petrarca (Mongibel; F. Petrarca, Triunfos, ed. Guido M. Capelli, Madrid, Cátedra, 2003, p. 191). 
$(L D)$-Almadrago(PI), Almadarol(LD)-Almaurol(PI), Brucalán $(L D)$-Brocalán $(P I), \quad$ y Madrusián $(L D)$-Dramusiando $(P I) .{ }^{27}$ De otro lado, se produce una presencia llamativa de antropónimos de gigantes formados por composición nominal: Almandrago, Cutroferón, Drusomago, Filesarfo, Mondragor, Nitroferón, Tersivandro o Zoandro, como sucederá también en el Silves de la Selva de Pedro de Luján, con gigantes como Astrobando, Bracafeo, Marcafeo, Marfondo, Mondrago o Monleo.

Por su parte, en el Amadís de Grecia prima la antroponimia gigantea de raíz grecolatina. Así, aparecen gigantes como Bravadanel (del latín pravus), Fraudalón (del latín fraus, fraudis), Fustión (del latín fusta), Leofán (del latín leo, leonis), o Mostruofurón (del latín monstrum + fera). Sin embargo, en la Primera y Segunda Parte de Florisel de Niquea y en la Tercera Parte de Florisel de Niquea hay una vuelta a la oscuridad del AG, con cierta preponderancia de la antroponimia germánica, como ocurre en el caso de Alastradolfo, Gadalón, Gadalote, Galpatrafo, o Gandalate, aunque también encontramos gigantes de nombre tan parlante como Brugiante.

Por último, en la Cuarta Parte de Florisel de Niquea, última entrega del ciclo, se produce un aumento del número de gigantes y una mezcla de todos los mecanismos del ciclo, con casos como el de Alastrasorón (del germánico alaster 'guerrero'), Brabosor, Espantolfo, Furibundo, Mordofeo, Mostruón o Serpentón.

A la luz de los datos anteriores, podríamos concluir que los antropónimos de los gigantes simbolizan la barbarie, la monstruosidad y la violencia extremas plasmada en una serie de raíces, que veremos a continuación, relativas a la fiereza (Nitroferón, Bruteo, Furior, Bravarte, Mostruón) o el pavor (Pavorante, Palidón), si bien algunos de ellos tienen un cariz claramente humorístico, como aquellos que expresan su fealdad o estulticia (Canifeo, Gadalfea, Espantolfo, Arlote). Estos se construyen a partir de diversos sufijos y formantes que contrastan con los nombres de caballeros y damiselas. ${ }^{28}$

\footnotetext{
27 Del mismo modo, el Palmerín presenta deudas antroponímicas claras con el Amadís de Gaula y las Sergas de Esplandián, algunas asimismo con reminiscencias artúricas, en los nombres de los personajes de Albaván (Albadán, AG), Carmelia (Carmela, Sergas), Danarín (Tanarín, AG), Dramarque (Madarque, $A G$ ), Espadrián (Esplandián, $A G$ ), Garín y Guarín (Garín, $A G)$, Grandalis (Brandalisa, $A G$ ), Grumedán, Guilán, Julianda, Languines, Leonorina y Olinda. Quizá esté presente la huella del Florisando en la figura de Floriana (Floriana de Estraváus, Florisando), o de otros géneros como la ficción sentimental con Lucenda, personaje homónimo de uno de los que da título al Tratado de amores de Arnalte y Lucenda (1491). En la mayoría de los casos los antropónimos solo han sufrido una pequeña variación gráfica o una metátesis, como sucede con Dramarque.

28 En los libros de caballerías la $a$ y la $o$ son habituales en la composición de los nombres propios de gigantes, junto con el sufijo aumentativo -ón (Furión, Mostruón, Dramadón), mientras que la $i$ y la $e$ o los sufijos diminutivos lo son, fundamentalmente, de los antropónimos femeninos (Leonorina, Leonoreta, Estrelleta, Luscida) o de enanos o escuderos cuyo nombre se ha construido muchas veces por medio del sufijo -ín (Durín, Gandalín, Laurín).
} 
En el caso masculino predomina sin lugar a dudas el sufijo aumentativo -ón con un total de treinta y cuatro casos (Alastrasorón, Brutillón, Cutroferón, Forón, Furión, Grafión, Naçarón, Palidón, Satirón, Turón, etc.), seguido de -án (Albadán, Braforán, Brucalán, Famongomadán, Gasquilán, Madrusián, Sizirfán, etc.), -el (Andaguel, Argantadel, Bravadanel, Gadancuriel, Masfandel, etc.), -eo (Breo, Burdeo, Macareo, Mordafeo, Mordobuseo, etc.), -a(r)que (Cartadaque, Lindoraque, Madarque, Lisnadoque), -nte (Basagante, Pavorante, Grifilante, Brugiante) u -ote (Arlote, Gadalote, Galeote).

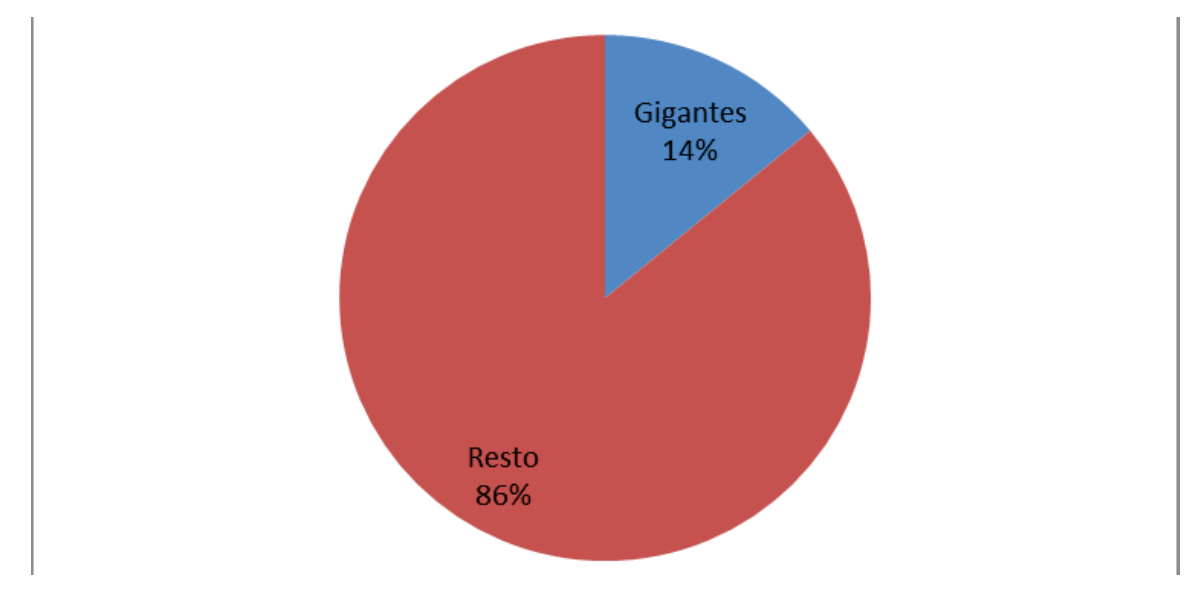

Gráfico 3. Porcentaje total de gigantes de sexo masculino en el ciclo amadisiano

En el caso femenino, solo encontramos un total de diecinueve gigantas, cuyos nombres no muestran una primacía compositiva. No hay un sufijo predominante. Al comienzo del ciclo se aprecia la tendencia a emplear el aumentativo -ona (Andandona, Arcalona), y después se construyen conforme al resto de antropónimos femeninos, mediante los sufijos -ea (Gadalfea, Malfadea), -inda (Brucarinda, Galacinda) o -asa/esa (Batalasa, Gadalesa, Gadabalassa).

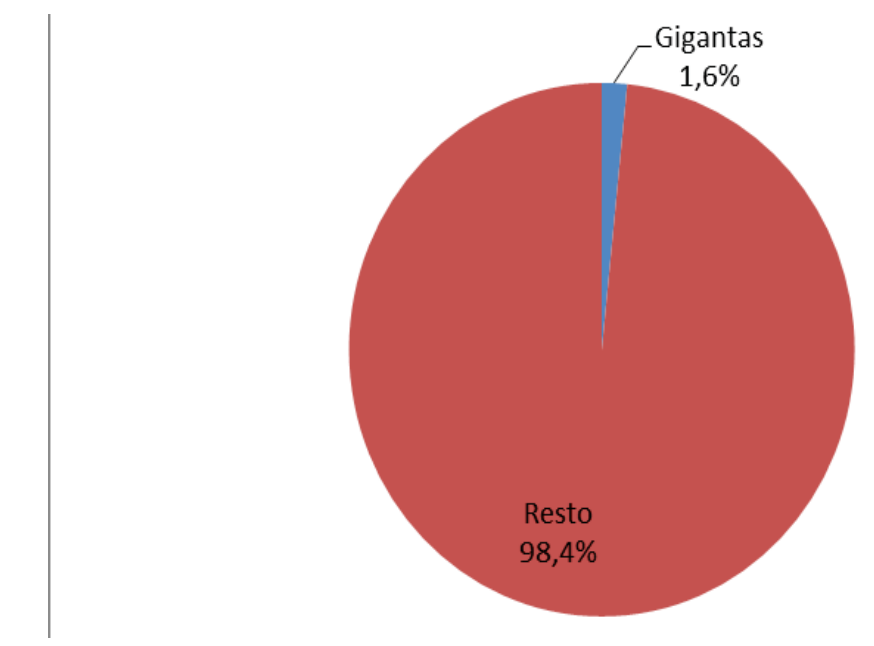

Gráfico 4. Porcentaje total de gigantas en el ciclo amadisiano 


\section{Hacia una poÉtica de la ANTROPONimia gigantea caballeresca}

El carácter maniqueo de protagonistas y antagonistas queda reflejado en sus antropónimos. Al escuchar el nombre de un gigante el lector o auditorio adivinaría al instante su condición. Asociados a la maldad y al vicio, se trata de seres desproporcionados y desmesurados física y moralmente. Si los protagonistas se caracterizan por el orden, la belleza o la armonía, estos lo harán por el desorden, la monstruosidad y el caos, características que comparten con los monstruos y que se plasmarán en sus nombres.

En cuanto a la desmesura física, prima la agresividad que deriva en la barbarie (Barbarán, Bruteo, Bruterbo, Brutillón), la bravura (Bravarte, Brabosor, Bravanadel), la furia (Furibundo, Furior, Furión), la fiereza (Nitroferón, Cutroferón) o determinadas expresiones verbales exacerbadas (Bramarte, Bramato, Brugiante). De otro lado, es habitual la referencia a su fealdad (Canifeo, Bracafeo, Gadalfea, Marcafeo, Mordofeo) y/o monstruosidad (Mostruón y Mostruofurón). ${ }^{29}$

En cuanto a la desmesura moral, se suele recurrir a su estulticia (Arlote), su maldad (Malabraçán), y el miedo o pavor que provocan en sus circundantes (Espantolfo, Palidón y Pavorante), aunque en ocasiones se revisten de tintes humorísticos. ${ }^{30}$

En cuanto a los sobrenombres de los gigantes, estos van en la misma dirección que los antropónimos. Podríamos clasificarlos en aquellos que hacen referencia a sus principales características físicas (el Fuerte, el Brun, el Gigante, de las Fuerzas, de la Roxa Barva, el Feo, el Grande, el Viejo, el Bermejo) o a su comportamiento (el Follón, el Bravo, el Salvaje, el Triste, el Soberbio, el Dudado). ${ }^{31}$ Se observa un predominio de la presencia de sobrenombres de gigantes precisamente en las continuaciones heterodoxas, el $F$, el $L D$ y el $S S$, aquellas en las que ya hemos visto cómo la importancia de esta raza era significativamente mayor que en el resto de entregas.

\footnotetext{
29 La construcción de los nombres de gigantes es similar en todos los libros de caballerías. Así, encontramos a Brutandel en el Florando de Inglaterra, o Brutervo y Brutón en el Lidamor de Escocia, haciendo referencia a su brutalidad; a Brabadalte en el Lidamor o Bravaleo en el Valerián de Hungría, a su bravura; a Furoldán en el Felixmarte, o Furiandro o Furiano en el Febo el troyano, a su furia; a Fieronte en el Febo, o Bucífero en el Clarián, a su fiereza; a Rodofeo en el Espejo de príncipes y caballeros, a su fealdad; o a Mostrón en el Lidamor, a su monstruosidad.

30 Lo mismo sucede en el resto de libros de caballerías con gigantes como Maloto, del Clarián de Landanís.

31 Se trata de los siguientes gigantes: Balaín el Salvaje $(L D)$, Balán el Salvaje $(L D)$, Bracafeo el Feo $(S S)$, Bracino el Grande (SS), Bragadán el Bermejo (LD), Bravor el Brun (AG), Brucalán el Bravo (LD), Brusín el Grande (SS), Enceleo el Montés $(L D)$, Ficarón el Fuerte (F), Gadalón de las Fuerças (FNIII), Galtazar de la Roxa Barva (FNIII), Gasquilán el Follón $(A G)$, Grovalaz el Negro, el Gigante $(L D)$, Macareo el Triste $(L D)$, Madarán el Soberbio (FNIII), Madrusián el Gigante (LD), Mangadón el Bravo (SS), Marcafeo el Feo, el Dudado (SS), Marfondo el Grande (SS), Mostruón el Viejo (FNIV), Orián el Crespo (F), Turón el Fuerte $(F)$.
} 


\section{ConClusiones}

La importancia del gigante es indiscutible en el ciclo amadisiano, llegando a equipararse en algunos momentos su cifra con el número de mujeres. De enorme presencia en todo el ciclo, algunos autores como Páez de Ribera y Juan Díaz le conceden una mayor relevancia, del mismo modo que Feliciano de Silva en su última entrega, en la que encontramos reunidos y ampliados todos los elementos que nos han acompañado a lo largo de los centenares de páginas que la preceden.

Si bien el gigante arquetípico se caracteriza por su monstruosidad, su soberbia y su fiereza, hemos visto cómo su perfil se va enriqueciendo, hallando gigantes buenos o perfeccionados tras su conversión al cristianismo. El caso más singular es el de las gigantas o jayanas, habitualmente hermosas y virtuosas como las damas y doncellas arquetípicas del género caballeresco.

En cuanto a sus nombres, prima la construcción mediante el sufijo aumentativo -ón, que refuerza su tamaño y sus características en grado sumo, así como una serie de raíces o formantes, normalmente de procedencia grecolatina, que atienden a su desmesura física (brutalidad, fealdad, monstruosidad, fiereza) y moral (maldad, pavor, estulticia), sin olvidar los tintes humorísticos que encierran algunos de ellos y llegarán a su grado sumo en la parodia cervantina quijotesca con gigantes como Pandafilando de la Fosca Vista, Malambruno o Brandabarbarán de Boliche.

\section{BiblografíA}

Acero Yus, F., «Los gigantes en el Quijote de Cervantes: revisión de un motivo de la literatura caballeresca», Espéculo: Revista de Estudios Literarios, 32 (2006), sin paginación.

<https://pendientedemigracion.ucm.es/info/especulo/numero32/gigantes.html> Avalle-Arce, J. B., Amadís de Gaula: el primitivo y el de Montalvo, México, Fondo de Cultura Económica, 1990.

Baranda, N., Historias caballerescas del siglo XVI, Madrid, Biblioteca Castro, Turner, 2 vols, 1995.

Campos Rojas, A., «Hermosos y comedidos gigantes en los libros de caballerías hispánicos: Flor de caballerías», en Jesús Cañas Murillo, Francisco Javier Grande Quejido y José Roso Díaz (eds.), Medievalismo en Extremadura. Estudios sobre literatura y Cultura Hispánicas de la Edad Media, Cáceres, Universidad de Extremadura, 2009, pp. 489-498.

Cervantes, M. de, Don Quijote de la Mancha, dir. Francisco Rico, Barcelona, Galaxia Gutenberg, 2004. 


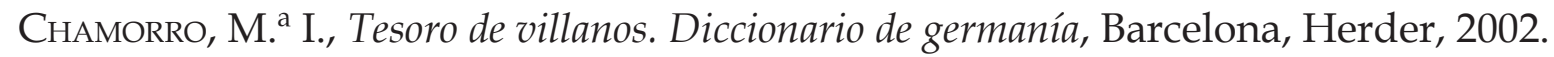

Coduras, M., La antroponimia en los libros de caballerías españoles: el ciclo amadisiano, Zaragoza, Universidad de Zaragoza, 2013. <http:/ / zaguan.unizar.es/record/12557/files/TESIS-2013-108.pdf>

Cuesta Torre, M. ${ }^{a}$ L., «Nuevas formulaciones del tópico del caballero soberbio en el Olivante de Laura de Antonio de Torquemada», en La maravilla escrita. Antonio de Torquemada y el Siglo de Oro, coords. Juan Matas Caballero, José Manuel Trabado Cabado, León, Universidad de León, 2005, pp. 321-342.

-------, «"Si avéis leído o leyerdes el libro de don Tristán y de Lançarote, donde se faze mención destos Brunes": Bravor, Galeote y el Caballero Anciano del Tristán castellano en el Amadís de Montalvo», en «Amadís de Gaula»: quinientos años después. Estudios en homenaje a Juan Manuel Cacho Blecua, eds. José Manuel Lucía Megías, María Carmen Marín Pina; col. Ana Carmen Bueno, Alcalá de Henares, Centro de Estudios Cervantinos, 2008, pp. 147-173.

DíAz, J., Lisuarte de Grecia. El octavo libro de Amadís, que trata de las estrañas aventuras y grandes proezas de su nieto Lisuarte, y de la muerte del ínclito rey Amadís, Sevilla, Jacobo y Juan Cromberger, 1526.

Lucía Megías, J. M., «Sobre torres levantadas, palacios destruidos, ínsulas encantadas y doncellas seducidas: de los gigantes de los libros de caballerías al Quijote», Artifara. Sección Monographica, 2 (2003), sin paginación.

<http:/ / www.cisi.unito.it/artifara/rivista2/testi/gigantes.asp>

Luján, P. de, Silves de la Selva. La dozena parte del invencible cavallero Amadís de Gaula, que tracta de los grandes hechos en armas del esforçado cavallero don Silves de la Selva con el fin de las guerras ruxianas..., impr. Dominico de Robertis, Sevilla, 1546.

LunA MARISCAL, X., «El gigante ausente: transformación y pervivencia de un tema literario en las historias caballerescas breves», en Aurelio González, Lilia von der Walde y Concepción Company (eds.), Temas, motivos y contextos medievales, México, El Colegio de México-Universidad Nacional Autónoma de MéxicoUniversidad Autónoma Metropolitana, 2008, pp. 45-59.

------, Índice de motivos de las Historias caballerescas breves, Vigo, Editorial Academia del Hispanismo, 2013.

Márquez Villanueva, F., «El tema de los gigantes», en Fuentes literarias cervantinas, Madrid, Gredos, 1973, pp. 297-311.

MARTín Romero, J. J., «El combate contra el gigante en los textos caballerescos», en Rafael Alemany, Josep Lluís Martos y Josep Miquel Manzanaro (eds.), Actes del X Congrés Internacional de l'Associació Hispànica de Literatura Medieval (Alacant, 1620 setembre de 2003), Alacant, Institut Interuniversitari di Filologia Valenciana, 3, 2005, pp. 1105-1120. 
-------, «" ¡O captivo cavallero!" Las palabras del gigante en los textos caballerescos», Nueva Revista de Filología Hispánica, 56.1 (2006), pp. 1-31.

PÁez de Ribera, Florisando. El sexto libro del muy esforçado y grande rey Amadís de Gaula, en que se recuentan los grandes y hazañosos fechos del muy valiente y esforçado cavallero Florisando, príncipe de Cantaria, su sobrino, fijo del rey Florestán, Salamanca, Juan de Porras, 1510.

Petrarca, F., Triunfos, ed. Guido M. Capelli, Madrid, Cátedra, 2003.

Rodríguez de Montalvo, G., Amadís de Gaula, ed. Juan Manuel Cacho Blecua, 2 vols., Madrid, Cátedra, 1988.

-------, Sergas de Esplandián, ed. Carlos Sainz de la Maza, Madrid, Castalia, 2003.

Silva, F. de, Primera y Segunda Parte de Florisel de Niquea. Corónica de los muy valientes y esforçados cavalleros don Florisel de Niquea y el fuerte Anaxartes, hijos del muy excelente principe Amadís de Grecia, emendada del estilo antiguo según que la escribió Zirfea, reina de Argines, por el grande amor que a sus padres tuvo, que fue traducida de griego en latín y de latín en romance castellano por el muy noble cavallero Feliciano de Silva, Valladolid, impr. Juan de Espinosa y Nicolás Tierri, 1532.

SILVA, F. de, La Primera y Segunda Parte de la Cuarta de la Crónica del excellentíssimo príncipe don Florisel de Niquea, Salamanca, impr. Andrés de Portonaris, 1551.

------, Florisel de Niquea (Tercera parte), ed. Javier Martín Lalanda, Alcalá de Henares, Centro de Estudios Cervantinos, 1999.

------, Lisuarte de Grecia, ed. Emilio J. Sales Dasí, Alcalá de Henares, Centro de Estudios Cervantinos, 2002.

-------, Amadís de Grecia, eds. Ana Carmen Bueno Serrano y Carmen Laspuertas Sarvisé, Alcalá de Henares, Centro de Estudios Cervantinos, 2004.

\section{Recursos en línea}

Base de datos Clarisel: <http:/ / clarisel.unizar.es $>$

Diccionario de Autoridades: <http:/ / corpus.rae.es/cordenet.html>

Diccionario de la Real Academia (DRAE): <http:/ / lema.rae.es/drae/>

DINAM: <http:/ / dinam.unizar.es/> 